\title{
Reflections on Scaffolding and Semiotic Challenge
}

\section{Commentary on Flood}

\author{
Ellice Ann Forman \\ University of Pittsburgh, Pittsburgh, PA, USA
}

\author{
Keywords \\ Classroom discourse $\cdot$ Scaffolding $\cdot$ Sociocultural theory
}

Virginia Flood reminds us of the insights that Vygotsky provided about the bidirectional process of integrating everyday and academic concepts in classroom discussions. These insights are fundamental to understanding the processes of teaching and learning [Saxe, de Kirby, Kang, \& Schneider, 2015]. Flood is not alone in recognizing the timelessness of Vygotsky's theorizing. Periodically, others have expressed surprise at its continued relevance [Davydov, 1995] and have argued that his work continues to address important problems facing education [Mahn \& John-Steiner, 1998; Roth \& Lee, 2007]. Discussions of the learning mechanisms that help students make sense of academic concepts continue to appear in articles that mention Vygotsky's theory quite briefly [e.g., Heller \& Morek, 2015].

Flood's [this issue] microanalysis allows us to reexamine the social learning mechanisms by which adults use speech and gesture to create and sustain shared understanding or intersubjectivity with children. She cites Wertsch's [1985] microanalyses of how an adult helps a young child assemble a truck puzzle task as creating "temporarily shared social realities" (p. 160) via the mechanism of semiotic challenge. In an example from the truck puzzle activity, the child refers to a puzzle piece as a cracker and the adult responds by calling it a wheel. She argues (following Wertsch) that the child initially views the piece as if it was a pretend piece of food (everyday concept) but encounters the adult's different perspective on the puzzle piece as a functional part of the truck puzzle as a whole (academic concept). This mismatch of expectations creates a semiotic challenge for the child that could lure her into accepting the adult's version of the truck puzzle.

Although the truck puzzle example in the context of a tutoring session may appear dissimilar from the examples of discussion orchestration via revoicing in a classroom setting discussed by O'Connor and Michaels [1993, 1996], the learning mecha-

KARGER @ 2018 S. Karger AG, Basel
E-Mail karger@karger.com
www.karger.com/hde


nisms may be related. In their work, O'Connor and Michaels identified how teachers use revoicing to repeat, expand, refine, or translate student utterances so that they can effectively participate in academic discussions. For example, during an elementary school classroom discussion about how to compute the perimeter of a hexagonal figure, a student might use the everyday terms such as "I counted all around the edges." The teacher then could revoice this student by translating her speech into the mathematically precise term "perimeter" [Strom, Kemeny, Lehrer, \& Forman, 2001]. As O'Connor and Michaels argue, revoicing not only requires the student to acknowledge the mismatch between her speech and that of her teacher, it also recognizes the student's authority to contribute her ideas to the collective activity of the group.

Flood appreciates that some readers might prefer to use scaffolding [Wood, Bruner, \& Ross, 1976] instead of semiotic challenge to characterize the learning mechanisms behind both the tutoring and classroom examples. Like Stone [1993], she acknowledges the limitations of the scaffolding metaphor (as typically employed in education). In addition, she connects Stone's critique of scaffolding with the semiotic challenges identified by Wertsch [1985]. Furthermore, she uses these arguments about the learning mechanisms in conversation to motivate her own microgenetic analysis of multimodal revoicing. Although I fully support Flood's expanded analysis of revoicing to include nonverbal components of communication, I believe that further clarification is needed about the nature of semiotic challenge in speech. The aim of my brief commentary is to illustrate, with examples from our research on classroom discourse, Stone's proposal for an expanded version of the scaffolding metaphor. My goal is to use these illustrations to help us better understand the learning mechanisms inherent in revoicing and similar classroom talk moves by teachers and students.

In their original article about scaffolding, Wood, Bruner and Ross [1976] studied adult-child tutoring sessions using a block construction task similar to the truck puzzle discussed by Wertsch [1985]. Wood et al. [1976] identified the six functions of scaffolding as recruitment, reduction in degrees of freedom, direction maintenance, marking critical features, frustration control, and demonstration. These functions showed how an effective tutor shared task responsibilities with a novice block builder (young child), allowing her to achieve with assistance more than she could achieve on her own. This was accomplished by directing the child's attention, by motivating and encouraging her, and by sharing the cognitive load. This type of assistance was seen as temporary and should disappear as the novice becomes more proficient [Stone, 1998]. Recent discussions of scaffolding continue to focus on many of the same functions (e.g., marking critical features) [Reiser \& Tabak, 2014].

Stone's [1993, 1998, 2002] critique of the scaffolding metaphor concerned the nature of the original task analysis and the anticipated aim of scaffolding. The initial analysis by Wood et al. [1976] used a tower building task (smaller wooden blocks fit together into a square that needed to be placed on top of larger blocks that fit together in the same fashion to create a pyramid form). This task required that the child work with minimal adult verbal direction but could be aided by adult nonverbal direction (placing two blocks together so that they fit correctly, organizing the block pieces by size). This was unlike the Wertsch task that involved more verbal direction

\footnotetext{
${ }^{1}$ This is an example of "nominalization - the use of a nominal form to express a process meaning" [Thompson, 2014, p. 238]. This is an important feature of the science register [Halliday \& Martin, 1993].
}

Reflections on Scaffolding and Semiotic Challenge
Human Development 2018;61:174-180 DOI: $10.1159 / 000490159$ 
(e.g., about shapes, colors or functions of the puzzle pieces) as well as nonverbal direction (pointing out a block and where it fits in the puzzle form). Thus, the tower building task could be completed with limited conversation. The truck puzzle, by contrast, required semiotic mediation (by design) in which confusions over cracker and wheel would require speech to overcome. Successful completion of the tower task did not require intersubjectivity between the tutor and the novice: the novice did not need to see the finished product as a pyramid. Successful completion of the truck puzzle did require intersubjectivity: agreement that the finished product represents a truck.

One of Stone's [1993] publications addressed the following question: "What is missing from the metaphor of scaffolding?" (p. 169). In this book chapter, he connected scaffolding to Vygotsky's concept of the zone of proximal development and acknowledged that some of the original authors (Wood and Bruner) also drew parallels between the two concepts. For example, both concepts investigate the processes by which children's independent problem solving can be enhanced through the assistance of a more knowledgeable other. Nevertheless, Stone [1993] argued that scaffolding omitted a careful examination of the semiotic mechanisms of the learning process whereas the zone of proximal development depends upon sign mediation that was crucial to Vygotsky's theory [Moll, 2014; Wertsch, 1985].

In a later publication, Stone [2002] offered his own expansion of the scaffolding metaphor by emphasizing three features: context, contingency, and challenge. He proposed that context referred to the attentional and affective functions of scaffolding (such as frustration control or recruitment). The power of contingency is that the adult control depends upon the changing nature of the child's understanding of the situation. In other words, the adult increases her assistance when the child struggles and fades her help when the child is able to act on her own. Previous studies of scaffolding in education have frequently focused on its attentional and affective functions and the notion of contingency [van de Pol, Volman, \& Beishuizen, 2010] but few studies highlight challenge. For Stone, semiotic challenge is required if intersubjectivity between the teacher and student(s) is to be achieved.

How does semiotic challenge occur in teaching situations? One example of semiotic challenge occurs when the teacher's talk moves violate the conventional conversational maxims identified by Grice [1989]. Grice was interested in how we interpret the informal logic (e.g., conversational implicatures) in everyday conversation. He recognized that we tend to follow a Cooperative Principle when we converse that obeys the maxims of quantity, quality, relation, and manner. In other words, we attempt to make our contribution informative (quantity); we try to be truthful (quality); we make our comments relevant to the topic being discussed (relation); and we try to be clear and brief (manner).

Of course, violations of these maxims frequently occur in humor, parody or irony, but breaking the rules serves to foreground our collective acceptance of the Cooperative Principle. One salient example is the familiar rhetorical question: "Is the Pope Catholic?" By acknowledging that this question does not require an answer, we demonstrate our shared understanding of the rules governing valid requests and replies. When teachers violate the Gricean maxims, they can send a message to their students that the informal rules of conversation have changed, such as when they insist upon an academic register instead of the rules of informal conversation [Forman \& Larreamendy-Joerns, 1998]. 
The example mentioned earlier of the teacher revoicing a student's utterance about "counting around the edges" by substituting "perimeter" violates the Gricean maxims of quantity and manner. This is because those two utterances mean the same thing but they belong to different speech registers (everyday vs. academic). The implicit challenge of this instance of revoicing is that different rules may apply in classroom conversations.

It is important to note that semiotic challenge in revoicing does not just involve substituting one academic vocabulary word for a phrase (i.e., nominalization). It can also occur when the teacher expands a student's utterance using additional academic vocabulary words. One example from a middle school mathematics classroom occurred after a student, Larry, provided the answer to a problem as " $171 / 2$ centimeters" and the teacher revoiced him by substituting " 17 1/2 squared centimeters" [Forman, Larreamendy-Joerns, Stein, \& Brown, 1998, p. 535]. This expansion was crucial because her instructional goal for the lesson was to help the students transfer their prior knowledge of linear measurement (one dimension) to area measurement (two dimensions), which meant that the unit must change from centimeters to squared centimeters. Although Larry initially acknowledged his agreement with his teacher's expansion, he continued to frame the task as about linear measurement until later in the lesson. After several other students made the same mistake, the teacher and some of their classmates had to explicitly frame the problem as one of area measurement since the implicit framing had not achieved its instructional aim for everyone. Thus, this teacher's use of scaffolding was contingent as well as challenging.

Another way that semiotic challenge occurs in classrooms during scaffolding is when the teacher decides to change the classroom authority structures. Tabak and Baumgartner [2004] identified two different ways that teachers and students interact in classrooms during discussions of academic content: mentor or partner. They referred to these interaction patterns as participation structures. In typical classrooms, the teacher is the primary intellectual authority (the holder of the correct answers and the person who controls the conversational floor). This is the mentor participation structure, which follows an asymmetrical pattern of authority and activity. The teacher asks known-answer questions, the students answer her questions and the teacher evaluates their answers. This is the familiar three-part classroom conversational structure of initiation by the teacher, response by the students, and evaluation by the teacher or I-R-E [Cazden, 2001]. In contrast, the partner structure is more symmetrical because the teacher shares her authority with her students. The partner participation structure is rare in classrooms and requires a dramatic shift in speech and activity.

In one innovative classroom studied by Forman, Ramirez-DelToro, Brown, and Passmore [2017], there was a dramatic shift in participation structure over the course of a 9-week elective course in evolutionary biology. The teacher in this high school classroom challenged her students to assume greater authority and control over the orchestration of classroom discourse by rearranging the seating (from all chairs facing the front of the room to all chairs placed in a circle) and by violating the mentor conversational norms. She violated these norms during one lesson late in the course by declaring that her students should act as if she had left the classroom (thereby giving them control of the conversational floor) and moving behind the circle of students. This not only violated the mentor norm of asymmetrical control by the teacher, it also violated the Gricean conversational maxim of quality (since she announced 
that she was leaving but she remained in the room). The instructional goal of this lesson was particularly difficult because the students were required to critique their classmates' use of Darwin's theory to explain the history of protective mimicry in two unrelated species of butterflies ${ }^{2}$. In previous lessons, artificial data was created to simplify the students' task. In this particular lesson, actual data was presented for analysis and critique. Thus, the teacher challenged her students to take on the intellectual and managerial authority of the partner structure as if she were absent to simulate the conditions of authentic scientific inquiry [Chinn \& Malhotra, 2002].

Later on in the same lesson, the students found themselves in the awkward position of trying to counter each other's scientific arguments when they actually agreed more than disagreed. (All of them focused on wing coloration.) This was demonstrated by their speech patterns (long pauses between turns) and nonverbal communication (gaze aversion). After an extended period of struggle, the teacher made some suggestions for reorienting the discussion in a more productive direction. In response, her students used humor to question her bid for authority: "Are you here now? Where's that voice coming from?” These responses were short-lived because the students seemed to recognize that the teacher's intellectual authority was needed at this point in their discussion.

The teacher responded by suggesting that her students consider the kinds of evidence they would need to come up with alternative explanations for the phenomena. When her hints were not successful, she described a recent study by biologists that invalidated all the students' arguments about the importance of wing color ${ }^{3}$. The students quickly recognized that this experiment had disproven their earlier explanations. Suddenly, the nature of the discourse radically changed (short or no pauses between turns) as they attempted to find evidence for different explanations such as taste or odor. Thus, the teacher's mastery of contingency, context and challenge was demonstrated by her ability to toggle seamlessly from requiring students to take charge and intervening when they struggled.

Almost a century later, Vygotsky's insights about the importance of integrating children's prior knowledge (everyday concepts) and academic discourse (academic or scientific concepts) continue to be relevant to instruction in schools [Forman \& Shekell, in press; Saxe et al., 2015]. Nevertheless, educators have often oversimplified or misunderstood his ideas [Stone, 1998]. One misrepresentation is that scaffolding is frequently stripped of its connections to semiotic mediation, a feature that was central to Vygotsky's related concept of the zone of proximal development [Stone, 1993]. Flood's microanalysis of a tutoring session reminds us of the value of Vygotsky's original ideas and their later developments in the work of Wertsch, Stone, and others. She also expands these ideas about semiotic challenge to include other literatures such as gesture analysis that allow us to see the elaborate dance that occurs during teaching and learning along multiple modalities (e.g., speech, gesture, prosody, pacing, and physical positions). In our own research on classroom discourse, we have incorporated distinctions from applied linguistics, such as revoicing, nominalization, conver-

\footnotetext{
2 The two species are Monarch and Viceroy butterflies that exhibit very similar wing colors. Monarchs are poisonous to their predators (birds); Viceroys are not poisonous. Birds avoid eating both species.

${ }^{3}$ When the biologists removed the wings from the butterflies in their study, their predators avoided eating the two species that had exhibited similar wing colors.
} 
sational maxims, and participation structures, to help us uncover the subtle cues that are interpreted (or misinterpreted) during fast-paced classroom instruction.

All of us have benefited from the affordances of new technologies that allow us to uncover the hidden features of communication in complex social environments. Flood's valuable analysis of a tutoring session and her expansive review of the literature of learning by participation may help future investigators build upon Vygotsky's ideas as well as weave together the disparate theoretical threads needed to help us conceptualize the complicated dynamic of intersubjectivity in educational settings.

\section{References}

Cazden, C.B. (2001). Classroom discourse: The language of teaching and learning (2nd ed.). Portsmouth, NH: Heinemann.

Chinn, C.A., \& Malhotra, B.A. (2002). Epistemologically authentic inquiry in schools: A theoretical framework for evaluating inquiry tasks. Science Education, 86, 175-218. doi:10.1002/sce.10001

Davydov, V.V. (1995). The influence of L.S. Vygotsky on education theory, research, and practice. Educational Researcher, 24, 12-21. doi:10.3102/0013189X024003012

Forman, E.A., \& Larreamendy-Joerns, J. (1998). Making explicit the implicit: Classroom explanations and conversational implicatures. Mind, Culture, and Activity, 5, 105-113. doi:10.1207/ s15327884mca0502_4

Forman, E.A., Larreamendy-Joerns, J., Stein, M.K., \& Brown, C.A. (1998). "You're going to want to find out which and prove it": Collective argumentation in a mathematics classroom. Learning and Instruction, 8, 527-548. doi:10.1016/S0959-4752(98)00033-4

Forman, E.A., Ramirez-DelToro, V., Brown, L., \& Passmore, C. (2017). Discursive strategies that foster an epistemic community for argument in a biology classroom. Learning and Instruction, 48, 32-39. doi: 10.1016/j.learninstruc.2016.08.005

Forman, E.A., \& Shekell, C. (in press). Promoting dialogic discussion in mathematics and science classrooms. In R. Gillies (Ed.), Promoting academic talk in schools. New York, NY: Taylor \& Francis.

Grice, P. (1989). Studies in the way of words. Cambridge, MA: Harvard University Press.

Halliday, M.A.K., \& Martin, J.R. (1993). Writing science: Literacy and discursive power. Pittsburgh, PA: University of Pittsburgh Press.

Heller, V., \& Morek, M. (2015). Academic discourse as situated practice: An introduction. Linguistics and Education, 31, 174-186. doi:10.1016/j.linged.2014.01.008

Mahn, H., \& John-Steiner, V. (1998). Introduction to Concepts, contexts, and transformation: Scientific and everyday concepts revisited. Mind, Culture, and Activity, 5, 81-88. doi:10.1207/ s15327884mca0502_1

Moll, L.C. (2014). L.S. Vygotsky and education. New York, NY: Routledge.

O'Connor, M.C., \& Michaels, S. (1993). Aligning academic task and participation status through revoicing: Analysis of a classroom discourse strategy. Anthropology and Education Quarterly, 24, 318-335. doi:10.1525/aeq.1993.24.4.04x0063k

O'Connor, M.C., \& Michaels, S. (1996). Shifting participant frameworks: Orchestrating thinking practices in group discussion. In D. Hicks (Ed.), Discourse, learning, and schooling (pp. 63-103). New York, NY: Cambridge University Press. doi:10.1017/CBO9780511720390.003

Reiser, B.J., \& Tabak, I. (2014). Scaffolding. In K. Sawyer (Ed.), The Cambridge handbook of the learning sciences (2nd ed., pp. 44-62). New York, NY: Cambridge University Press. doi:10.1017/ CBO9781139519526.005

Roth, W.-M., \& Lee, Y.-J. (2007). "Vygotsky's neglected legacy:” Cultural-historical activity theory. Review of Research in Education, 77, 186-232. doi:10.3102/0034654306298273

Saxe, G., de Kirby, K., Kang, B., \& Schneider, M.L.A. (2015). Studying cognition through time in a classroom community: The interplay between "everyday" and "scientific concepts". Human Development, 58, 5-44. doi: 10.1159/000371560

Stone, C.A. (1993). What is missing in the metaphor of scaffolding? In E.A. Forman, N. Minick, \& C.A. Stone (Eds.), Contexts for learning: Sociocultural dynamics in children's development (pp. 169-183). New York, NY: Oxford University Press.

Stone, C.A. (1998). The metaphor of scaffolding: Its utility for the field of learning disabilities. Journal of Learning Disabilities, 31, 344-364. doi:10.1177/002221949803100404

Reflections on Scaffolding and Semiotic Challenge
Human Development 2018;61:174-180 DOI: $10.1159 / 000490159$ 
Stone, C.A. (2002). Promises and pitfalls of scaffolding instruction for students with language learning disabilities. In K.G. Butler \& E.R. Silliman (Eds.), Speaking, reading, and writing in children with language learning disabilities (pp. 175-198). Mahwah, NJ: Lawrence Erlbaum Associates.

Strom, D., Kemeny, V., Lehrer, R., \& Forman, E.A. (2001). Visualizing the emergent structure of children's mathematical argument. Cognitive Science, 25, 733-773. doi:10.1207/s15516709cog2505_6

Tabak, I., \& Baumgartner, E. (2004). The teacher as partner: Exploring participant structures, symmetry, and identity work in scaffolding. Cognition and Instruction, 22, 393-429. doi:10.1207/s1532690Xci2204_2

Thompson, G. (2014). Introducing functional grammar (3rd ed.). London, UK: Routledge.

van de Pol, J., Volman, M., \& Beishuizen, J. (2010). Scaffolding in teacher-student interaction: A decade of research. Educational Psychology Review, 22, 271-296. doi:10.1007/s10648-010-9127-6

Wertsch, J.V. (1985). Vygotsky and the social formation of mind. Cambridge, MA: Harvard University Press.

Wood, D., Bruner, J.S., \& Ross, G. (1976). The role of tutoring in problem solving. Journal of Child Psychology and Psychiatry and Allied Disciplines, 17, 89-100. doi:10.1111/j.1469-7610.1976.tb00381.x 